\title{
Researching Communicative Figurations: Necessities and Challenges for Empirical Research
}

\section{Christine Lohmeier and Rieke Böbling}

\subsection{INTRODUCTION}

What is the best way to research a communicative figuration? How can we approach a communicative figuration as a cross-media phenomenon? And who belongs to a communicative figuration and who does not? To answer such broad and general questions, it is helpful to discuss them by considering specific examples such as cultural communities. In a past research project, one of the authors of this chapter investigated the media of the Cuban American community in Miami (Lohmeier 2014). The main questions guiding the investigation were how different

C. Lohmeier $(\bowtie) \cdot$ R. Böhling

ZeMKI, Centre for Media, Communication and Information

Research, University of Bremen, Bremen, Germany

e-mail: christine.lohmeier@uni-bremen.de

R. Böhling

e-mail: rieke.boehling@uni-bremen.de

(C) The Author(s) 2018

A. Hepp et al. (eds.), Communicative Figurations,

Transforming Communications - Studies in Cross-Media Research, https://doi.org/10.1007/978-3-319-65584-0_14 
media contributed to creating a sense of belonging or fragmentation, and which actors were in charge of media as institutions and in terms of media content. Questions about the meaning of community and belonging, such as the ones mentioned above, arose again and again during processes of data gathering and analyses. At the time of research, the Cuban American community was fragmented, heterogeneous, dispersed into several locations within the USA with strong ties to a diasporic community spread across the world. Making decisions on which groups within the Cuban American community to focus on, which newspaper articles and posts to read and whose words to listen to was not an easy task. No doubt querying the choices one makes in the research process is in fact an essential part of the process. One might even argue that researchers need questions such as these in order to produce valuable and critical work.

When considering this research project as a whole, employing the approach of communicative figurations as a tool for data gathering as well as for analyses and findings of the research might have proven useful for a number of reasons: First, the concept of community is highly abstract. Even if we can agree on a definition of what a community is, working with this understanding on the ground is another matter. Because, second, the realities of a community are complex, diverse, even messy, we could say. Returning to the example of the Cuban Americans in Miami, the community was fragmented by generational differences and distinct experiences of migration; there were segments of the community with a lot more financial muscle and political ambitions than others. Some did not feel represented or welcome at all, while others were living the American dream. Were all these individuals and sub-groups part of the same community? Third, communities are in a constant state of flux. Some individuals purposefully decided to leave Miami and the Cuban American community behind. Does this end their belonging to the community as a whole?

The concept of communicative figurations as we outline it in this volume could have mitigated some of the described problems. For one, it helps to operationalize our understanding of community and thereby makes it more easily 'workable'. Furthermore, owing to its scalability, it leaves room to account for the complexity and diversity of communities. Relatedly, and finally, communicative figurations are never static but always have the potential to change, and can be thought of as fluid. 
That said, approaching communities as figurations is a helpful starting point. But at the same time, working with a figurational approach brings its own set of methodological requirements and challenges. There are two necessities and challenges in particular of this approach we want to discuss here: first, conducting cross-media research as a necessity and challenge and, second, defining the boundaries of a communicative figuration as a necessity and challenge. In the final section of this chapter, we will consider a specific example to illustrate how a figurational approach can be employed. Again, we are taking into account the necessity of such an approach and possible challenges that (can) come with it. For all of these themes, our line of argument will address both the requirements as well as the challenges.

\subsection{Cross-Media as a Necessity and Challenge}

Communicative figurations are characterized by their actor constellations, frames of relevance and communicative practices, entangled with a media ensemble. In order to understand communicative figurations and their interdependencies on one another, it is essential to reconstruct the figuration by gathering data on the actors involved, the themes that are of significance to these actors and the practices that are shared and simultaneously constitute the figuration. Returning to the example of the Cuban American community in Miami, the task thus would be to gather information on the different actors who are part of the community as a communicative figuration, their frames of relevance and their communicative practices. As Hepp and Hasebrink explain in Chap. 1, the constellation of actors within a communicative figuration forms the 'structural basis' for the communicative figuration. In the example, this includes a broad variety of actors who can be considered as making up part of the Cuban American community in relation to the city of Miami and its media, at first notwithstanding the generational differences, different experiences of the migration process, financial situations, diverse political ambitions and so on. These factors do not determine whether actors are part of a communicative figuration in the first place, but they do play into the relationship of the constellation of the actors to each other, and are thus an important factor when determining how the network within a communicative figuration is interrelated and how the different actors communicate with each other. The second dimension of 
the communicative figuration concerns the frames of relevance which define the 'topic' and therefore character of a communicative figuration as a social domain. In our example, the Miami media, including radio, $\mathrm{TV}$, blogs, social networks, and their interrelations and interactions with different segments of the community, would construct (be it as reader, listener, viewer, journalist, producer) frames that are of particular importance. Lastly, the communicative practices that are interwoven with other social practices in this specific case are very closely related to the second dimension: the frames of relevance. The question here would be how the different actors engage with Cuban American Miami media, while also taking into account the entire media ensemble of the communicative figuration.

One of the key methodological advantages of conceptualizing social sites through a figurational approach lies in its constitutive parts: the three distinct dimensions which make up a figuration provide a framework for operationalizing research questions. In addition, the figurational framework supports a process of data gathering that is simultaneously open, on the one hand, but not arbitrary, on the other. The required balance between these two poles in the processes of data gathering is especially relevant when considering the limits of the field that is being researched or when selecting a sample. As stated in the introduction of this chapter, defining a community is difficult. The Cuban American community is fragmented, and it is difficult to define the whole spectrum of people belonging to a specific community. We will devote some more attention to the fringes of a figuration in Sect. 14.3.

However, there are certain challenges related to this kind of research, and one main challenge is its cross-media point of view. The figurational approach implies that a variety of data needs to be collected across a variety of media. To make these points more specific, let us consider Ien Ang's (1985) seminal work on television audiences in Watching Dallas. When Ang was working on her study in the early 1980s, she considered Dallas and the appropriation of the series by the people. Data was mainly gathered through encouraging audience members to write letters to the researcher about their viewing experience and their opinions of Dallas. While Ang's approach was at the forefront of 'new audience research', which received momentum from the mid-1980s onwards- together with work by David Morley (1980), John Fiske (1990) and Philip Schlesinger et al. (1992) - the methodology employed and the data brought together by Ien Ang leave a number of questions unanswered: In which 
context did audience members watch Dallas? With whom would they discuss the programme? In which other practices might Dallas and the experiences of watching Dallas be embedded? In which areas of daily life might the overall themes of the series and the themes of individual episodes be of relevance and relate to, contradict and oppose other relevant themes? And especially, is it possible to research the appropriation of the series without considering its relation to other kinds of media? David Morley was already pointing towards questions like this in 1992, when he called for a new type of research:

The kind of research we need to do involves identifying and investigating all the differences behind the catch-all category of 'watching television' ... we do need to focus on the complex ways in which television viewing is inextricably embedded in a whole range of everyday practices... We need to investigate television viewing ... in its 'natural setting'. (Morley 1992: 177)

The 'natural setting' in which television viewing takes place has diversified over the past decades. Given the many ways in which television is consumed nowadays, considering one show in one medium through one type of methodological approach gives a limited perspective on social life, and can therefore only serve to consider one specific aspect of the lifeworlds of individuals. Of course there have been methodological developments which have in some way or other answered David Morley's call for a more nuanced style of research. One such example is the volume put forward by Berker et al. (2006). Relating to and building on the domestication approach, the collection takes a wider view of the home and the interrelation between media and technologies in the home. They focus on 'the continuity of routines and patterns of everyday life, but also consider the breaking of routines and the discontinuity of some processes' (Berker et al. 2006: 3).

If we apply the figurational approach to Ang's study, we might ask how Dallas relates to other media consumed and appropriated, who the different actors in the family home are, how they relate to a particular programme and how they communicate with each other and with other actors about the programme, a specific episode, and the specific themes it raises. In the current state of deep mediatization, these questions should be broadened to take into account other mediated interactions that take place in relation to the viewing of a programme. If we identify the media ensembles and communication practices of different actors within a 
figuration, we can expect that additional actor constellations come into play in a state of deep mediatization. A one-dimensional approach would neglect these factors.

Methodological discussions of cross-media research are not new to media and communication scholarship. Kim Christian Schrøder (2011) provides a comprehensive overview of the development of cross-media research and studies employing a cross-media research design. Schrøder argues that a cross-media approach is not optional or a 'nice-to-have' when approaching audience research. He sees it as an essential part of a research design to capture what audiences or users of any kind are experiencing in their engagement with media. Says Schrøder (2011: 6):

I shall therefore claim that a genuine audience perspective on the contemporary media culture must adopt a cross-media lens, because people in everyday life, as individuals and groups, form their identities and found their practices through being the inevitable sense-making hubs of the spokes of the mediatized culture. [...] Audiences are inherently cross-media.

Even though the final sentence of the quote might seem like stating the obvious, a cross-media approach is still not the norm for many research projects.

While the benefits of conducting research from a cross-media perspective are hard to refute, a high volume of studies in the field of media and communications work mainly with one specific type of data such as media texts (content analysis) or data gathered through interviews, to name but two examples. Our point is not to say that these studies are not of value or do not serve to answer certain types of research questions. In line with Schrøder (2011: 7): 'Some will play the game of cross-media research on the front stage of their research theatre; for others the crossmedia perspective will and should remain a backstage thing.' Given the changes that have been observed in the media landscape over the past decades, it is necessary to reflect upon the validity and the meaningfulness of research focusing on a single medium or one type of data only. What we aim to emphasize is that the figurational approach allows for a holistic picture of the interrelationship between what we have traditionally thought of in different domains of study within communication and media studies: texts, audiences, uses, practices, and actors and production. By doing so, it takes questions of communication research to a broader level, positioning them in social contexts without falling into the trap of pursuing mediacentric research (Livingstone 2009). 
Conducting research from a cross-media perspective gives rise to a number of challenges. For one, it forces researchers to gather data in different ways through different methods and to think of different ways of data gathering, data mining and relating diverse types of data to each other. We will present a detailed approach to how this can be achieved in the final section of this chapter. Secondly, combining data in such a way implicates ethical questions. One example is that-similar to network analysis - we might have some findings referring to people who have never agreed to take part in the research process. How can this be dealt with responsibly? The plus side promises a cross-media approach for triangulation and a richer set of data. Then again, different types of data are likely to call for different methods of analysis, meaning more time and thought will have to be devoted to the analyses. ${ }^{1}$

\subsection{Defining Boundaries as a Necessity and Challenge}

Another necessity as well as a challenge of research that we want to draw attention to is that of defining the boundaries of who and what is being researched. In other words, it is a matter of defining and deciding who belongs to a certain figuration and who does not. While the immanent characteristics of a communicative figuration (actor constellation, significant themes and practices) give the researcher indications of who is part of a communicative figuration and who is not, grey areas in which a decision has to be made are to be expected. Take as an example a company with headquarters in Berlin and subsidiaries in Amsterdam and Singapore. The data gathered so far might indicate that there are frequent meetings between staff from all locations. Similar topics are also deemed important in the three offices. However, it turns out that the work practices differ significantly between Amsterdam and Berlin, on the one hand, and Singapore, on the other. In such a case, can we still assume all three offices to be part of one figuration?

As discussed by Couldry and Hepp (2017: 72-76), figurations of figurations can be observed in different constellations. Often, media, and more recently the internet and social networking sites in particular, enable the construction of figurations of figurations - think of social movements that operate to a great extent through the use of internet platforms. In figurations of figurations, actors themselves 'can be considered as figurations' in their own right. In the example mentioned above, each team within a company can be considered a figuration which as a 
whole forms part of a larger figuration. For figurations of figurations to come into existence and function in a meaningful way, mediated communication and a shared media ensemble are crucial (Couldry and Hepp 2017: 73). A second principle that allows figurations of figurations to exist is a meaningful arrangement in the Weberian sense. More specifically, as Couldry and Hepp (2017: 74) explain, figurations of figurations are based upon and within 'certain discourses that connect these figurations and their meaning in the social world, and certain larger scale relations of interdependency between domains of action [...] that come to be associated with assumed relations of meaning' (emphasis in the original). Going back to the example of the transnational company with offices in Berlin, Amsterdam and Singapore, it might be useful to conceptualize this type of organization as a figuration of figurations.

In ethnographic studies, the researched is commonly referred to as 'the field' (Nxss 2016). Several scholars have pointed towards the difficulties of defining where the field begins and where it ends-especially in an increasingly complex social and largely mediated world (for example Lohmeier 2014; Lohmeier in press; Mitchell 2012). Hans Erik Næss (2016: para. 2) emphasizes this point when he writes:

In contrast to the conventional view on the field as a territorial unit, [I argue that it] should be seen as composed of several sites, processes and relations - sometimes far from each other geographically and connected with each other in different ways, on different scales and with different intensity. A field consequently, is where the phenomenon can be said to exist. Sites are localities where you can investigate the processes, actions and relations within this phenomenon ethnographically.

In a similar line of argument, Eva Nadai and Christoph Maeder (2005: para. 10) state that 'unlike traditional cultural anthropology sociological ethnography in and of complex societies rarely ever deals with a clearly bounded group in a single place'. They (Nadai and Maeder 2005: para. 24) conclude the article by arguing that the main advantage of such multi-sited ethnographies are the generalizations that can be drawn from the research: 'By using multi-sited ethnography we can enlarge the traditional "single tribe, single scribe" way of doing ethnographic research and contribute to sociological questions that cut across the boundary of a single traditional field.' 
To illustrate these points, let us take research on families as an example. At first sight one might consider the family a rather straightforward and easily definable field as well as an easily definable figuration. However, under closer scrutiny, defining what makes a family is not an easy task. As pointed out in The Blackwell companion to the sociology of families (Scott et al. 2004) we can observe a pluralization from family to families. The editors state: 'Our title acknowledges the plurality of family forms and, by implication, the dynamic process of family formation and dissolution across time' (Scott et al. 2004: xvii). Recent research on families (see for example Jamieson et al. 2014) has acknowledged the complexities of families. Transnational family networks, as they have been researched by Madianou and Miller (2012) and Beck-Gernsheim (2014), are but one example of the growing diversity of families. In addition, these studies have shown that the complexities increase with the recent development in media change. In line with the broader definition of family in academia, research participants might similarly have shifting understandings of who belongs to their family, depending on circumstances. In a recent action research project with teenage refugees based in Bremen (Volmerg et al. 2016), participants were creating family-like relations with each other as well as with at least one of the researchers involved.

Definitions of the family are certainly dependent on historical and cultural contexts. As Morgan (2014) points out, the changing definition of family is partly thanks to changing circumstances and the fluidity of social life, and partly to the changing perceptions of what can constitute a family. From a methodological point of view, the difficulty of defining families at the point of data gathering might seriously limit the data gathering process by imposing a set definition of families from the outside. By conceptualizing families as figurations, researchers can consider their actor constellations, relevance frames and practices and thereby construct families through a multi-perspective lens. The concept of communicative figurations can therefore be used to sharpen the understanding of what 'the field' one wants to research is, by not neglecting fluidities within a figuration but by illuminating them.

Another requirement when applying a figurational approach to a field of study is that it allows for scalability. As Couldry and Hepp (2017: 70) point out: 
Certain types of figuration-associated with distinctive ensembles of media technologies-generate obligations and dependencies not just between individuals, but also between individuals and communication systems, obligations that are distinctive features of how we live within the media manifold, but which also characterize new types of figuration.

To this end, it is also crucial to pay attention to various interrelations between figurations. Couldry and Hepp (2017) provide an example in which they situate the figuration of the family within its web of figurations. In the context of raising and educating children, a family interacts over many years with organizations (schools, adult education centres, universities) that are regarded as having certain responsibilities for education' (Couldry and Hepp 2017: 75). These children, in turn, grow up and form part of various figurations themselves while probably staying connected to the communicative figuration of the family. Hence, Couldry and Hepp (2017: 75) speak of an 'ever-expanding, indeed changing, set of other figurations (and figurations of figurations)'. Some of these external figurations might consist of other human actors, while others might come into being through techno-human interaction. An example for these techno-human actors might be dating sites, whose algorithms suggest people with similar interests and supposedly matching character traits as potential future partners.

From an empirical perspective, researching figurations and figurations of figurations provides a whole new set of challenges. One is to gain an understanding of the figuration as a whole and to understand how it functions with others who might not be based in the same location. For one, this might call for mobile methods (Büscher and Urry 2009), a methodological approach that we will return to in Sect. 14.4. Depending on the research project, it might secondly call for developing new kinds of methodologies. Building up expertise in digital methods, including working with so-called 'big data', is without doubt a significant development in this area (Rogers 2013). However, even though we might find ourselves in a land of plenty when it comes to digital traces and digital data in general, it does not mean that all questions are easily answered (Lohmeier 2014). One of the current challenges is to combine and bring together data gained through digital traces with data stemming from the (material) context in a meaningful way (Hine 2015). This requires learning new skills, and developing new programmes and apps that allow for and support such data gathering (Hasebrink and Hepp 2017; 
Hepp et al. 2016). For some types of research question, this could also mean working in interdisciplinary and transnational teams, which in turn comes with its own advantages and hurdles. ${ }^{2}$

So far, we have considered some of the necessities and challenges when approaching research with a figurational approach in mind. In particular, we have focused on cross-media research and how the fringes of a field and the periphery of a figuration can be defined. In the remainder of this chapter we aim to integrate what we have elaborated on by outlining a specific research project.

\subsection{Researching Mediated Family Memory}

The arguments we provided for conducting cross-media research as well as for defining boundaries of the research field as necessities when researching today's media environment and the challenges we have identified for these two necessities is rather abstract. We will now move on from the methodological considerations and present an ideal research project that addresses and illustrates in more detail some of the advantages and challenges we have outlined so far by means of this specific project. The overall theme of the project is family memory; that is, we ask how memory is constructed in the context of the family in times of deep mediatization. Taking both cross-media research as well as the issue of defining boundaries seriously, the methodology of this project is designed to gain a diverse set of data by involving ethnographic miniatures and collected mediated memory objects. Furthermore, we involve participants in the research process by asking them to take an active role in the process of data gathering.

\subsubsection{Researching Mediated Family Memory: Cross-Media and the Boundaries of the Figuration}

Two key features of today's media environment are that the practices of a given figuration are mediated through a media-manifold and related to non-mediated practices as well. From a methodological point of view, this calls for a cross-media perspective which also takes non-mediated objects, places and other sites of the social into account. According to Büscher and Urry (2009): 
Methods also need to be able to follow around objects, what Marcus calls 'follow the thing' (1995). This is because objects move as part of world trade which increasingly involves complex products; objects move in order to be combined into other objects (such as the components of a computer that travel the equivalent of a journey to the moon); some objects travel and lose their value (cheap souvenirs) while others enhance their value through movement (an 'old master': Lury 1997); and as objects travel, their cultural significance can grow as they accrete material and symbolic elements (107).

A figurational perspective can encompass the material aspects of life and the social as it unfolds while at the same time recognizing the current state of deep mediatization. On a methodological level, this means accepting a wider and possibly explorative approach when reconstructing a figuration in a first instance. This is not to imply that more standardized approaches to researching communicative figurations are not possible. It does, however, mean that a figuration is considered with an appropriate degree of openness in the first instance. Methodological approaches such as so-called 'mobile methods' (Büscher and Urry 2009) can provide a good way into this approach. Mobile methods is a way into the empirical where a researcher is 'trying to move with, and to be moved by, the fleeting, distributed, multiple, non-causal, sensory, emotional and kinaesthetic' (Büscher et al. 2011: 1).

In this 'ideal' project, we investigate the communicative construction of memories and mnemonic practices in the context of families in a state of deep mediatization. We distinguish between group, public and personal memories and work with a diverse sample of families: locally situated and with a migrant background, as well as traditional, blended and alternative. ${ }^{3}$ As an overall framework, we view the family as a communicative figuration in order to understand the different ways in which memories are constructed by taking into account actor constellations, frames of relevance and communicative practices.

\subsubsection{A Concrete Example: Reconstructing Communicative Figurations Through Interviews and a Multi-Situated Ethnographic Approach}

To gain insights into families as communicative figurations and in order to understand the communicative construction of memories within locally situated and migrant families, this project employs a 
mixed-method design that includes interviews and a multi-situated, online and offline ethnography. Second, we employ a qualitative content analysis and sorting techniques that allow us to categorize digital and material memory objects relevant for the researched families. Third, throughout the whole process research participants are encouraged to get involved and support the process of data gathering. This means that they can contribute relevant (mediated) memory objects and share them with the researchers.

Drawing on Larsen $(2005,2008)$, Büscher and Urry (2009: 107) explain the required openness and mobility in the most literal sense for the case of researching memories:

$[\mathrm{m}]$ uch mobility involves the active development and performances of 'memory' that 'haunt' people, places and especially meetings. Recovering such memories necessitates empirical methods that qualitatively investigate how photographs, letters, images, souvenirs and objects are deployed within large social groupings or within family and friendship groups.

They also point towards the "'atmosphere' of place or places" (2009: 106)-especially of the home. However, depending on the research questions and the figuration in focus, this might equally apply to an office building, a community hall, a school or university building or a public square where meetings and gatherings take place.

To reconstruct the communicative figurations of families-that is the actor constellations, communicative practices and frames of relevance-we embark on a multi-situated ethnographic approach (Beneito-Montagut 2011). This means participating in family gatherings, accompanying families on outings or spending time with them collectively or individually during regular activities. The combination of interviews and ethnographic encounters allows for a holistic picture of families as communicative figurations and their practices of communication with regard to the construction of memories. This view is central in our approach to families, as communicative figurations might or might not function as a collectivity to communicatively construct, share, exchange and negotiate family and public memories. The guiding questions are therefore as follows: Who is involved in the communicative practices of the family as a figuration? Who participates in relation to which themes, and what are the frames of relevance for the family? More broadly, how is a sense of group identity and a sense of belonging 
created through communication practices and a shared media ensemble? Who is constructed as part of the family by whom? Which actors dominate or have a central role in constructing the family? As part of these extended multi-situated ethnographic miniatures (Bachmann and Wittel 2006), we conduct interviews with members of each family. In these semi-structured interviews, we assess first the communicative practices within the family. In addition, we gather data on the mnemonic practices of the family. To embed the data gathered through interviews in a wider context, we employ a multi-situated, online and offline ethnographic approach. In particular, this involves spending time with the family in their home, on outings, befriending members of the family on networking sites, and participating as much as possible in their everyday lives.

Secondly, we focus on digital and material memory objects that are of relevance to research participants. The guiding questions for this part of the research process are as follows: How are memories communicatively constructed within different types of families? How do different lifestyles and other circumstances (such as mobility and flight) impact on families' memory practices? What is considered valuable in such situations? How do different families approach the construction of memories? By asking these types of questions, researchers can ensure to conduct peoplerather than media-centred research (Hepp 2010). Moreover, researchers will gain access to an extensive collection of memory objects through the interviews and the ethnographic fieldwork conducted. Through this step, we will first gain insights into the different types of digital and material memory objects, the interplay between digital and material memory objects and their relevance within the communicative construction of the family. Second, the focus moves on to what types of memories the objects point to. Are they related to group memory (including family celebrations and commemorations, such as christenings, weddings and remembrances of deceased family members), public memory (such as national holidays and remembrance days, visits to a museum), and more personal, private and intimate family memories (such as favourite meals, hiding places in the house or names of dolls and teddy bears).

Finally, within this methodological approach, participants are encouraged to gather additional data relevant for the research projects. This could be pictures of material memory objects that they would like to tell us about or pictures taken at family gatherings. While the pictures are memory objects in and of themselves, they allow for a continued conversation between researchers and research participants that will bring 
deeper insights into the nature of the communicative and mnemonic practices. In an ideal scenario, participants will also record conversations at family gatherings or at the dinner table, similar to the data analyzed by Keppler (1994). Data gathered in this way will be analyzed by drawing on a conversation analysis (Keppler 1994; Bergmann and Luckmann 1995).

What becomes apparent with this methodology is that by focusing on actors and practices, we are required to take a cross-media approach, as these are the circumstances in which the communicative construction of memories takes place. Moreover, focusing on actors and thereby taking a people-centred perspective assists us in understanding the figuration and its limits. This type of methodology serves to understand in greater depth the various aspects of research participants' lifeworld experiences when it comes to family memory.

\subsection{Conclusion}

In this chapter, we have addressed some underlying questions related to approaching a research project with the notion of communicative figurations. We have done so by considering both the requirements as well as the challenges when it comes to doing cross-media research and to defining the field and its limits.

In particular, we have addressed what doing cross-media research entails. There are still only a relatively small number of projects that take the call for a cross-media approach seriously. This is not entirely surprising, as cross-media research does come with a number of challenges, some of which we have outlined above. Moreover, cross-media research does take time, effort and deviation from well-known methodological paths. The concept of communicative figurations provides a useful tool that assists researchers in thinking through their research process and how to go about it with a cross-media perspective. Gathering data on actors involved, frames of relevance and communicative practices is highly likely to include various media. Thus, the concept itself assists by focusing on more than one kind of media. This does not mean that the data are spread equally across all media sustained or used by the actors of the communicative figuration, but the approach does open up a wider perspective. On the other hand, this is not to say that a study whose main bulk of data analyses tweets, for example, cannot be of value or be based on a communicative figuration. 
The second challenge we addressed was defining the boundaries of the field. We have illustrated how the concept of communicative figurations can be utilized to assess how researchers might be able to define the boundaries of the researched field without neglecting its inherent complexities and open-ended character. The concept of communicative figurations proves useful in this regard for a number of reasons. By allowing the researcher to focus on a specific set of characteristics, namely, actor constellations, frames of relevance and communicative practices, the process of de-marking a figuration is relatively clear cut and applicable for a variety of research topics. Nonetheless, as the approach also allows for the characterization of figurations of figurations, the complexities of a figuration are also taken into account.

In the latter part of the chapter, we have given a detailed example of how a broad research question regarding the communicative construction of family memory can be operationalized. Our project, on family memory, asks broadly how memory is constructed in the context of the family. Our approach takes into account the cross-media reality of families' lifeworlds by its methodological approach, and our field's boundaries are defined by taking the figuration of the family and considering its interdependencies with other figurations, as well as possible figurations of the figuration. All in all, the design of the project is reconstructing closely the (communicative) realities of today's lifeworlds in a time of deep mediatization.

\section{Notes}

1. Given the academic environments many scholars work in, however, spending more time on one particular study is not encouraged. On the contrary, from the strategic point of view of one's career, emerging scholars might be well advised to publish several papers (ideally peer-reviewed journal articles) from the set of data that was gathered quickly-Averbeck-Lietz and Sanko (2016) on the issue of time in academia. Perhaps this is part of the reason why developing cross-media research skills has not received the attention it deserves.

2. See for example Scheel et al. (2016) for a discussion of challenges and possible solutions when conducting a collaborative ethnography with researchers from various backgrounds.

3. Families consisting of two parents (mother and father) and a child or children are referred to as traditional. Blended families are those with two heterosexual partners with children from a previous marriage or partnership. 
Finally, alternative families consist of homosexual partners with adopted children or single parents. Other families-such as grandparents acting as main caregivers for children owing to the death of the parents-would also be included in the category of alternative families. We are keen to emphasize that we are not looking at different families from a normative point of view but value all forms of families and their members equally. We distinguish between the different types of families in order to recognize the diversity of the social world.

\section{REFERENCES}

Ang, Ien. 1985. Watching Dallas. Soap opera and the melodramatic imagination. London: Methuen.

Averbeck-Lietz, Stefanie, and Christina Sanko. 2016. Wissenschafts- und Forschungsethik in der Kommunikationswissenschaft. In Handbuch nicht standardisierte Methoden in der Kommunikationswissenschaft, eds. Stefanie Averbeck-Lietz and Michael Meyen, 125-136. Wiesbaden: Springer VS.

Bachmann, Götz, and Andreas Wittel. 2006. Medienethnographie [Media ethnography]. In Qualitative Methoden der Medienforschung [Qualitative methods of media research], eds. Ruth Ayaß, and Jörg R. Bergmann, 183-219. Reinbek: Rowohlt.

Beck-Gernsheim, Elisabeth. 2014. Transnationale Familien: Lebens- und Liebesformen in einer globalisierten Welt [Transnational families: Life and love forms in a globalized world]. In Die vergessenen Kinder der Globalisierung: Psychosoziale Folgen von Migration [The forgotten children of globalization: Psychosocial consequences of migration], eds. Elisabeth Rohr, Mechthild M. Jansen, and Jamila Adamou, 11-24. Giessen: Psychosozial-Verlag.

Beneito-Montagut, Roser. 2011. Ethnography goes online. Qualitative Research 11 (6): 716-735.

Bergmann, Jörg R., and Thomas Luckmann. 1995. Reconstructive genres of everyday communication. In Aspects of oral communication, ed. Uta Quasthoff, 68-86. Berlin, New York: de Gruyter.

Berker, Thomas, Maren Hartmann, Yves Punie, and Katie Ward. 2006. Domestication of media and technology. Maidenhead: Open University Press.

Büscher, Monika, and John Urry. 2009. Mobile methods and the empirical. European Journal of Social Theory 12 (1): 99-116.

Büscher, Monika, John Urry, and Katian Witschger. 2011. Mobile methods. Abingdon, New York: Routledge.

Couldry, Nick, and Andreas Hepp. 2017. The mediated construction of reality. Cambridge, Malden, MA: Polity Press. 
Fiske, John. 1990. Women and quiz shows: Consumerism, patriarchy and resisting pleasures. In Television and women's culture: The politics of the popular, ed. Mary E. Brown, 134-143. London, Newbury Park, CA: Sage.

Hasebrink, Uwe, and Andreas Hepp. 2017. How to research cross-media practices? Investigating media repertoires and media ensembles. Convergence, online first.

Hepp, Andreas. 2010. Researching 'mediatized worlds': Non-mediacentric media and communication research as a challenge. In Media and communication studies. Interventions and intersections, eds. Nico Carpentier, Ilija Tomanić Trivundža, Pille Pruulmann-Vengerfeldt, Ebba Sundin, Tobias Olsson, Richard Kilborn, Hannu Nieminen, and Bart Cammaerts, 37-48. Tartu: Tartu University Press.

Hepp, Andreas, Cindy Roitsch, and Matthias Berg. 2016. Investigating communication networks contextually. Qualitative network analysis as cross-media research. MedieKultur 32 (60): 87-106.

Hine, Christine. 2015. Ethnography for the internet. London: Bloomsbury.

Jamieson, Lynn, Ruth Lewis, and Roona Simpson. 2014. Researching families and relationships. Reflections on process. New York: Palgrave Macmillan.

Keppler, Angela. 1994. Tischgespräche [Dinner conversations]. Frankfurt am Main: Suhrkamp.

Larsen, Jonas. 2005. Families seen photographing: The performativity of family photography in tourism. Space and Culture 8: 416-434.

Larsen, Jonas. 2008. Practices and flows of digital photography: An ethnographic framework. Mobilities 3: 140-160.

Livingstone, Sonia. 2009. On the mediation of everything: ICA presidential address 2008. Journal of Communication 59 (1): 1-18.

Lohmeier, Christine. 2014. Cuban Americans and the Miami media. Jefferson, NC: McFarland.

Lohmeier, Christine. in press. Zwischen "gone native" und "eine von uns": Reflektionen zu etischer und emischer Positionierung zum Forschungsfeld. In Auswertung qualitativer Daten in der Kommunikationswissenschaft, ed. Andreas Scheu. Wiesbaden: Springer VS Verlag.

Lury, Celia. 1997. The objects of travel. In Touring cultures: Transformations of travel and theory, eds. Chris Rojek, and John Urry, 75-95. London: Routledge.

Madianou, Mirca, and Daniel Miller. 2012. Migration and new media: Transnational families and polymedia. Abingdon, New York: Routledge.

Marcus, George E. 1995. Ethnography in/of the World System: The emergence of multi-sited ethnography. Annual Review of Anthropology 24: 95-117.

Mitchell, Jon P. 2012. Introduction. In Ethnographic practice in the present, eds. Marit Melhuus, Jon P. Mitchell, and Helena Wulff, 1-16. New York: Berghahn Books. 
Morgan, David H.J. 2014. Framing relationships and families. In Researching families and relationships. Reflections on process, eds. Lynn Jamieson, Ruth Lewis, and Roona Simpson, 19-45. New York: Palgrave Macmillan.

Morley, David. 1980. The 'nationwide' audience: Structure and decoding. London: BFI.

Morley, David. 1992. Television, audiences and cultural studies. London: Routledge.

Nadai, Eva, and Christoph Maeder. 2005. Fuzzy fields. Multi-sited ethnography in sociological research. Forum: Qualitative Sozialforschung 6 (3): Art. 28.

Næss, Hans E. 2016. Creating "the field": Glocality, relationality and transformativity. Forum: Qualitative Sozialforschung 17 (3): Art. 15.

Rogers, Richard. 2013. Digital methods. Cambridge, MA: MIT Press.

Scheel, Stephan, Baki Cakici, Francisca Grommé, Evelyn Ruppert, Ville Takala, and Funda Ustek-Spilda. 2016. Transcending methodological nationalism through transversal methods? On the stakes and challenges of collaboration. ARITHMUS Working Paper Series, Paper No. 1. doi:10.13140/ RG.2.2.33901.79842. http://arithmus.eu/wp-content/uploads/2015/02/ Scheel-et-al-2016-Transcending-method-nationalism_ARITHMUS-Workingpaper-1.pdf. Accessed 15 May 2017.

Schlesinger, Philip, Rebecca E. Dobash, Russell P. Dobash, and C. Kay Weaver. 1992. Women viewing violence. London: British Film Institute.

Schrøder, Kim C. 2011. Audiences are inherently cross-media: Audience studies and the cross-media challenge. Communication Management Quarterly 18: $5-27$.

Scott, Jacqueline, Judith Treas, and Martin Richards. 2004. The Blackwell companion to the sociology of families. Oxford: Wiley-Blackwell.

Volmerg, B. et al. 2016. Videoprojekt mit jungen Flüchtlingen als Gegenstand methodischer Herangehensweisen der Aktionsforschung [Video project with young refugees as subject of methodical approaches to action research]. Presentation at the University of Bremen on 28 June. 
Open Access This chapter is licensed under the terms of the Creative Commons Attribution 4.0 International License (http://creativecommons.org/licenses/ by $/ 4.0 /$ ), which permits use, sharing, adaptation, distribution and reproduction in any medium or format, as long as you give appropriate credit to the original author(s) and the source, provide a link to the Creative Commons license and indicate if changes were made.

The images or other third party material in this chapter are included in the chapter's Creative Commons license, unless indicated otherwise in a credit line to the material. If material is not included in the chapter's Creative Commons license and your intended use is not permitted by statutory regulation or exceeds the permitted use, you will need to obtain permission directly from the copyright holder.

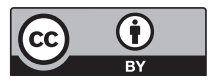

